* Mestrado em Direito Negocial pela Universidade Estadual de Londrina. Especialização em Direito do Consumidor pela Faculdade Damásio (2015-2016). Especialização em Direito Empresarial pela Universidade Estadual de Londrina (20122013). Especialização em Direito Aplicado pela Escola da Magistratura do Paraná (2011). Graduação em Direito pela Universidade Estadual de Londrina (2006-2010). Professor-Auxiliar da Pontifícia Universidade Católica do Paraná - Campus Londrina (2016 - atual). Professor do Curso Aprovação - Londrina (2016 - atual). Professor no Curso de Pós-graduação Lato Sensu - Especialização em Direito Aplicado da Escola da Magistratura do Paraná (2016). Professor do Curso SABER (2016). Professor do Curso Alfacon Concursos Públicos (2013). Analista Judiciário da Área Judiciária do Tribunal de Justiça do Estado do Paraná (2014 - atual). Advogado.

ruda_baptista@hotmail.com

\section{A Mitigação das Assimetrias Globais Socioeconômicas Pela Cooperação Internacional e Pelo Tratamento ESPECIAL E DifERENCIADo}

The Mitigation of Socio-economic Global Assimetries With International COOPERATION AND ESPECIAL AND DIFFERENTIALTREATMENT

\section{Rudá Ryuiti Furukita Baptista* Tânia Lobo Muniz**}

Como citar: BAPTISTA, Rudá Ryuiti Furukita. MUNIZ, Tânia Lobo. Amitigação das assimetrias globais socioeconômicas pela cooperação internacional e pelo tratamento especial diferenciado. Revista do Direito Público, Londrina, v. 12, n. 3, p.279-314, dez. 2017. DOI: $10.5433 / 1980-511$ X2017v12n3p279. ISSN: 1980-511X.

Resumo: A problemática do artigo se extrai da identificação no cenário internacional de desigualdades entre os Estados, em especial no que diz respeito ao nível de desenvolvimento e a concentração de riquezas destes que permite formular o seguinte questionamento: há prognóstico jurídico para a mitigação destas assimetrias globais? O tema se justifica na necessidade da promoção de um ambiente que garanta a igualdade material pela percepção das vulnerabilidades dos países menos desenvolvidos e em desenvolvimento. Para 
tanto, indica-se duas possíveis soluções: a) a concretização do princípio da cooperação internacional por meio de políticas de cooperação norte-sul e cooperação sul-sul; b) a adoção do tratamento especial e diferenciado no âmbito do sistema multilateral do comércio. A pesquisa se pauta na revisão doutrinária bibliográfica, cujo recorte teórico se concentra no âmbito do direito internacional econômico, bem como na análise de dados oficiais e classificações elaborados por instituições e organizações do direito internacional.

Palavras-chave: Assimetrias globais; Cooperação Internacional; Tratamento Especial e Diferenciado; Desenvolvimento Econômico

Abstract: The problematic of the paper is drawn from the identification on international scene of the inequalities among the States, in particular as regards the level of development and the concentration of wealth of these, which allows to formulate the following question: there is a legal prognosis for the mitigation of these global asymmetries? The theme is justified by the need to promote an environment that ensures material equality by understanding the vulnerabilities of the least developed and developing countries. To this end, it is indicated two possible solutions: (a) the implementation of the principle of international cooperation through policies of North-South cooperation and South-South cooperation, (b) the adoption of special and differential treatment under the
** Possui graduação em Direito pela Universidade Estadual de Londrina (1988), mestrado em Direito pela Pontifícia Universidade Católica de São Paulo (1997) e doutorado em Direito pela Pontifícia Universidade Católica de São Paulo (2004). Professora da Universidade Estadual de Londrina. lobomuniz@gmail.com 
multilateral trading system. The research utilizes a bibliographical doctrinal review, whose theoretical section focuses on international economic law, as well as on the analysis of official data and classifications elaborated by institutions and organizations of international law.

Key-words: Global asymmetries; International Cooperation; Special and Differential Treatment; Economic Development 


\section{INTRODUÇÃO}

O cenário internacional contemporâneo é permeado por um processo dinâmico de transformação alimentado pela globalização econômica. O redimensionamento do Estado e de seu aparato institucional frente aos desdobramentos deste fenômeno, que não segue critérios lógico-formais, é um desafio.

Hodiernamente, o direito internacional é influenciado por múltiplos fatores advindos de searas distintas, sendo que a rápida expansão de temas cada vez mais complexos tornam obsoletos os instrumentos do direito internacional clássico para lidar com os problemas atuais. Assim, cumpre ao direito internacional contemporâneo o papel de coordenar a atuação dos diversos atores e sujeitos de direito, a fim de garantir um ambiente equilibrado para a promoção do desenvolvimento mundial.

Neste contexto, destaca-se o problema central do presente trabalho, que se pauta no seguinte questionamento: se o atual cenário mundial, marcado pelas relações interestatais decorrentes da globalização econômica, propicia o aumento de desigualdades entre os países com graus díspares de desenvolvimento, pode-se formar uma perspectiva jurídica de prognóstico para superação destas assimetrias globais pela adoção da cooperação internacional e do tratamento especial e diferenciado?

Assim, o primeiro tópico terá a finalidade de trazer a lume o atual cenário internacional marcado pela presença de assimetrias globais decorrentes do fenômeno da globalização econômica. O objetivo, portanto, será traçar um diagnóstico para expor o movimento contemporâneo de intensificação das desigualdades, especialmente no que diz respeito à disparidade do nível de desenvolvimento entre países 
do mundo.

Para tanto, optar-se-á pela adoção dos seguintes índices: i) PIB per capita, sob a análise de dados da Conferência das Nações Unidas sobre Comércio e Desenvolvimento (United Nations Conference on Trade and Development - UNCTAD); ii) Índice de Desenvolvimento Humano (IDH) do Programa das Nações Unidas para o Desenvolvimento (PNUD); iii) Distribuição da riqueza no Relatório da Riqueza Global (Global Wealth Report) do Credit Suisse Research Institute.

Diante deste cenário, o segundo capítulo se destinará a apresentar a cooperação internacional como princípio jurídico capaz de nortear uma atuação que visa a mitigação das assimetrias globais, com vista a reorganizar a sociedade global mediante um agir mais solidário. Assim, desenvolver-se-á acerca do conceito da cooperação internacional, bem como se destacará a distinção de sua classificação entre Cooperação Norte-Sul e Cooperação Sul-Sul, para, ao final, elucidar os efeitos positivos decorrentes da concretização desta política de cooperação internacional na promoção do desenvolvimento dos países ao redor do globo.

Por fim, no terceiro tópico, será indicada a adoção do Tratamento Especial e Diferenciado (TED) como um instrumento jurídico capaz de diminuir as assimetrias globais e de propiciar um ambiente mais equilibrado, especificamente no campo do Sistema Multilateral do Comércio, por meio de uma exceção à regra do princípio da nãodiscriminação, que propicia justamente a discriminação dos países desenvolvidos dos países para beneficiar e promover os países em desenvolvimento e menos desenvolvidos. 


\section{ASSIMETRIAS GLOBAIS: ANÁLISE DAS DESIGUALDADES EXISTENTES NO CENÁRIO DA GLOBALIZAÇÃO}

No tópico inaugural se faz uma construção analítica de indicadores das assimetrias globais publicados por organizações internacionais que observam os graus de desenvolvimento econômico ${ }^{1}$ dos países, com base em critérios objetivos e subjetivos distintos, a fim de evidenciar as desigualdades existentes no plano internacional.

Para tanto, parte-se do preceito de que o processo de globalização econômica não é uniforme, não atinge todos os países da mesma maneira, e não atinge os que vivem no mesmo país do mesmo modo. O fenômeno da globalização, que pode surgir de imediato, como um processo de homogeneidade, é, de fato, um processo heterogêneo sob múltiplos aspectos (SPOSATI, 1997, p. 43).

Esta heterogeneidade é fonte de assimetrias globais que afetam as mais diversas áreas de apreciação. As assimetrias globais são, portanto, desigualdades sociais contemporâneas que se manifestam em diversos domínios, o que evidência seu caráter transversal derivado das conexões

1 Neste ponto, preliminarmente, esclarece-se que o conceito de desenvolvimento econômico recebe variações de correntes distintas da ciência jurídico-econômica. Na primeira vertente, associada a noção de uma solução simplificadora da realidade, emergem modelos que enfatizam apenas a acumulação de capital. Tal conceito indica a ideia de que o crescimento econômico engendra automaticamente o desenvolvimento econômico (SOUZA, 2012, p. 4). Em uma segunda vertente, pela qual se afirma que o desenvolvimento econômico não pode ser confundido com o crescimento econômico, destacam-se modelos de uma orientação crítica baseada na certeza de que o desenvolvimento econômico é decorrente de um conjunto de transformações intimamente associadas, que envolvem indicadores econômicos e sociais. No plano normativo internacional há ponto de referência que prima pela consolidação desta segunda corrente, pois a Declaração sobre o Direito ao Desenvolvimento de 1986 da Assembleia Geral da Organização das Nações Unidas prevê, em seu preâmbulo, que o desenvolvimento é um processo econômico, social, cultural e político abrangente, que visa o constante incremento do bem-estar de toda a população e de todos os indivíduos. Assim sendo, no trabalho em tela se observa a adoção do conceito desta segunda corrente, considerando que o desenvolvimento humano, em sentido lato, é o principal objetivo do desenvolvimento econômico. Assim, ambos podem ser atendidos mais eficazmente por perseguirem metas em conjunto através de políticas que estabelecem um equilíbrio entre os dois, e que levem em conta os seus efeitos diretos e indiretos em ambas as dimensões (UNITED NATIONS, 2014, p. 7). 
que estabelecem com os aspectos da vida social, complementares entre si (COSTA, 2012, p. 9).

Diante da pluralidade de possíveis objetos de observação das referidas assimetrias ou desigualdades globais, não se torna possível esgotar o conjunto infindável de indicadores e estudos que tratam do tema, razão pela qual no presente tópico optou-se pela escolha da análise de dados reportados e publicados por entidades que tradicionalmente realizam estudos neste campo do conhecimento, e, em especial, porque primam pela análise comparativa interdisciplinar.

Com efeito, o primeiro dado a ser analisado diz respeito a compreensão das desigualdades interestatais a partir da observação da disparidade na concentração de riqueza. Nessa linha ganha relevo a crítica no sentido de que "[...] a globalização econômica tem agravado ainda mais as desigualdades sociais, aprofundando-se as marcas da pobreza absoluta e da exclusão social" (PIOVESAN, 2002, p. 63).

A chamada globalização da pobreza está a processar-se durante um período de rápidos avanços tecnológicos e científicos. Enquanto contribuem para o incremento substancial da capacidade potencial do sistema econômico de produzir os bens e serviços necessários, os níveis de produtividade não se traduzem numa redução dos níveis de pobreza global (CHOSSUDOVSKY, 2003, p. 25).

Para tanto, optou-se pela análise anual de riqueza global denominada Global Wealth Report, elaborada pelo Credit Suisse Research Institute, que em 2016 chega a sua publicação de número setenta, considerada uma das principais fontes de inteligência em relação ao desenvolvimento da riqueza global, pois fornece estimativas extensas dos níveis globais de riqueza das famílias, abrangendo todas as regiões 
e segmentos populacionais ${ }^{2}$.

A referida pesquisa define o termo "riqueza" como o valor dos ativos financeiros mais imóveis (habitação) de propriedade das famílias, menos suas dívidas. $\mathrm{O}$ estudo centra-se na riqueza detida pela população adulta em mais de 200 países e compreendeu a riqueza de 4,8 bilhões de adultos (GLOBAL WEALTH REPORT, 2016).

$\mathrm{O}$ estudo aponta que nos últimos anos houve aumento na concentração da riqueza global nos países desenvolvidos ${ }^{3}$, o que, consequentemente, ensejou no aumento da concentração da pobreza nos países em desenvolvimento e menos desenvolvidos. Ao observar a pesquisa do ano de 2010 (GLOBAL WEALTH REPORT, 2010), referente ao ano mais remoto disponível no sítio eletrônico do referido instituto de pesquisa, tem-se que os países que compõem a Europa e a América do Norte juntos somavam $63 \%$ da concentração de riqueza global, enquanto os países situados nas Américas Central e do Sul juntamente com os países da África somavam 7\% da riqueza global. Entretanto, os dados do mesmo relatório no ano de 2016, ou seja, após um lapso temporal curto

2 No original: The Global Wealth Report, issued annually by the Credit Suisse Research Institute, is one of the key sources of intelligence in relation to global wealth development, and delivers extensive estimates of global household wealth levels, covering all regions and population segments (GLOBAL WEALTH REPORT, 2016) (tradução livre).

3 Neste ponto, indica-se que o conceito de "países desenvolvidos" foi extraído da classificação que observa o PIB per capita dos países, publicado pela Conferência das Nações Unidas sobre Comércio e Desenvolvimento, em inglês United Nations Conference on Trade and Development (UNCTAD) responsável por lidar com questões de desenvolvimento, nomeadamente o comércio internacional - o principal motor do desenvolvimento (UNCTAD, 2013) -, classificação esta disponibilizada no sítio eletrônico do órgão (UNCTAD, 2015). Nela os países são classificados em 05 classes. O Produto Interno Bruto (PIB), é uma medida agregada da produção igual à soma do valor acrescentado bruto de todas as unidades institucionais residentes envolvidas na produção (mais impostos e menos quaisquer subsídios aos produtos não incluídos no valor das suas saídas). Já o PIB per capita é justamente o valor do PIB dividido pela população do país. As cinco classes são dispostas conforme demonstrado a seguir: a) economias desenvolvidas (developed economies) com PIB per capita acima de U\$34.288; b) países em desenvolvimento (developing economies), que se subidividem em três espécies: b.1) economias em desenvolvimento de baixa renda (low-income developing economies) com PIB per capita abaixo de U\$1.142; b.2) economias em desenvolvimento de renda média (middle-income developing economies) com PIB per capita entre U\$1.142 e U\$5.141; b.3) economias em desenvolvimento de alta renda (highincome developing economies) com PIB per capita acima de U\$5.141; e, c) países menos desenvolvidos (least developed countries) com PIB per capita abaixo de U\$525. 
de apenas seis anos, indicam que os primeiros passaram a dotar de $65 \%$ da riqueza global e os últimos concentraram somente $5 \%$ desta riqueza.

No mesmo sentido, constata-se que em 2016 a desigualdade de riqueza, medida pela proporção dos 10\% mais ricos, em comparação com o restante da população adulta mundial, também aumentou. Em 2016, enquanto $50 \%$ da população possuía coletivamente menos de $1 \%$ da riqueza total, os $10 \%$ mais ricos possuíam $89 \%$ de todos os ativos globais. (GLOBAL WEALTH REPORT, 2016, p. 2) . $^{4}$

Além desta conclusão, expõe-se que $0,7 \%$ da população mundial (33 milhões de adultos) concentrava 45,6\% da riqueza mundial (116,6 trilhões de dólares), sendo que em 2010 esta mesma parcela da sociedade concentrava $35,6 \%$. Demonstra-se ainda que o equivalente a $1 \%$ da população mundial concentra metade de toda a riqueza do planeta ${ }^{5}$.

Com efeito, o Human Development Report (2016, p. 31), elaborado e publicado pelo Programa das Nações Unidas para o Desenvolvimento - PNUD (United Nations Development Programme - UNDP), que é a rede de desenvolvimento global da Organização das Nações Unidas presente em mais de 170 países e territórios, destaca nessa linha que entre 1988 e 2011 cerca de $46 \%$ do total de aumento da renda global ficou concentrado para os $10 \%$ mais ricos do mundo, sendo que desde de 2000, 50\% do aumento de riqueza global beneficiou apenas o $1 \%$ mais rico da população mundial ${ }^{6}$.

4 No original: We have further established that wealth inequality, measured by the share of the wealthiest $10 \%$ of adults, as compared to the rest of the world's adult population, continues to rise. While the bottom half collectively own less than $1 \%$ of total wealth, the wealthiest top $10 \%$ own $89 \%$ of all global assets (tradução livre).

5 Quanto ao tema se destaca o seguinte recorte midiático: "1\% da população mundial concentra metade de toda a riqueza do planeta". Disponível em: <"http://brasil.elpais.com/brasil/2015/10/13/ economia/1444760736_267255.html?rel=mas>. Acesso em: 08 abr. 2017.

6 No original: "Some 46 percent of the total increase in income between 1988 and 2011 went to the wealthiest 10 percent (figure 1.4). Since 2000, 50 percent of the increase in global wealth benefited only the wealthiest 1 percent of the world's population. Conversely, the poorest 50 percent of the world's population received only 1 percent 
Ademais, o Human Development Report (2016, p. 31) faz referência ao Relatório de Desenvolvimento Mundial de 2015 (World Development Report 2015: Mind, Society and Behavior) emitido pelo Banco Mundial, asseverando que entre 2008 e 2013 houve um aumento na diferença de renda em 34 países monitorados, à medida em que os rendimentos cresciam mais rapidamente para os mais ricos que para os mais pobres.

Desta forma, conclui-se que a riqueza global se concentra cada vez mais nos países desenvolvidos e de alta renda, e, há um aumento na concentração da riqueza global em favor de cada vez menos pessoas ${ }^{7}$. Tais fatores implicam, consequentemente, no aumento da pobreza dos países em desenvolvimento ou de baixa e média renda.

Trata-se, a partir da percepção da teoria sociológica ${ }^{8}$ de Goran Therborn (2010, p. 146), da desigualdade material ou de recursos, que é marcada pela dualidade "desigualdade de oportunidades" e "desigualdade de recompensa". A primeira se refere a desigualdade no acesso ao capital social, que acarreta na segunda, também denominada de desigualdade de resultado.

Entretanto, a análise isolada das assimetrias globais que dizem respeito a distribuição de riqueza e do produto interno bruto a nível mundial não é capaz de trazer a lume informação empírica elucidativa suficiente, razão pela qual cumpre identificar na configuração

of the increase" (tradução livre).

7 O Relatório Global de Riqueza de 2016 aponta que, em 2000, 96\% do dos 12,9 milhões de milionários do mundo se concentravam nos países desenvolvidos (de economia desenvolvida). No original: "The 12.9 million millionaires in the world in 2000 were heavily concentrated $(96 \%)$ in high income economies" (Global Wealth report, 2016, p. 20).

8 Integrando os contributos principais da análise sociológica a este respeito, Therborn sublinha com particular ênfase a pluralidade de desigualdades que caracteriza a configuração social contemporânea crescentemente globalizada. Propõe, neste sentido, uma perspectiva teórica de caráter multidimensional alargado, identificando três grandes conjuntos principais de dimensões de desigualdade no mundo atual, que designa por "desigualdades vitais", "desigualdades existenciais" e "desigualdades de recursos" (COSTA, 2012, p. 10). 
contemporânea da sociedade globalizada desigualdades em outras áreas.

Assim, outro critério utilizado para a observação das assimetrias entre os países é o Índice de Desenvolvimento Humano (IDH). Tal índice é um composto que mede a realização média em três dimensões básicas do desenvolvimento humano: 1) uma vida longa e saudável; 2) conhecimento; e 3) um padrão de vida decente. A fim de incluir estas dimensões, o IDH abrange a análise de subcritérios, quais sejam: a expectativa de vida, educação, alfabetização e rendimento, sendo que o nível de pobreza e igualdade também são tidos em conta (KASTENG; KARLSON; LINDBERG, 2004, p.15) ${ }^{9}$.

O Programa das Nações Unidas para o Desenvolvimento (PNUD ou United Nations Development Programme - UNDP), oferece uma perspectiva global aliada à visão local do desenvolvimento humano (PNUD, 2016), utiliza o IDH (em uma escala de 0 a 1 ) como critério para elaborar a classificação dos países do mundo, que se subdivide em: a) países com baixo desenvolvimento humano (Low Human Development) com IDH abaixo de 0,550 ; b) países com desenvolvimento humano médio (Medium Human Development) com IDH entre 0,550 e 0,699; c) países com desenvolvimento humano alto (High Human Development) com IDH entre 0,700 e 0,799; d) países com desenvolvimento humano super alto (Very High Human Development) com IDH acima de 0,800 (Human Development Report, 2016, p.193).

O Human Development Report 2016 revela que apesar da elevação de 20\% na média geral do IDH no período entre 1990 e 2015 , que passou dos 0,597 para $0,717^{10}$, os países com baixo desenvolvimento

9 No original: "The Human Development Index (HDI) is a composite index measuring average achievement in three basic dimensions of human development: (1) a long and healthy life; (2) knowledge; and (3) a decent standard of living. In order to include these dimensions, the HDI covers life expectancy, education, literacy and income; in addition, poverty and equality are taken into account." (Tradução livre)

10 No original: The progress since the first Human Development Report in 1990 demonstrates this. 
humano e países com desenvolvimento humano médio continuam com índices inferiores aqueles apresentados pelos países de desenvolvimento humano alto e super-alto.

Ainda, extrai-se do relatório (2016, p. 140) que a atual arquitetura das instituições internacionais e a desequilibrada evolução dos mercados globais apresentam desafios para o desenvolvimento humano. Isto porque, o capital tende a concentrar-se no segmento mais rico da população, que goza dos benefícios da mobilidade e das formas cada vez mais flexíveis de produção (cadeias de valor globais) ${ }^{11}$.

Portanto, indica-se que há uma visão difundida de que a globalização é boa para uma pequena elite, mas não para as grandes massas, razão pela qual muitos acadêmicos e políticos que acolheram a globalização estão revisando sua opinião. A reação contra a globalização está reformando a política em vários países, e, se não pode ser revertida, então o desafio é garantir que a globalização não deixe ninguém para trás (Human Development Report, 2016, p. 35) ${ }^{12}$.

O estudo indicou ainda que entre 1975 e 2010 houve redução da desigualdade global relativa, baseada no "Relative Gini coefficient", que passou de 0,74 para 0,63, entretanto, também demonstrou que houve aumento na desigualdade global absoluta, baseada no denominado "Absolute Gini coefficient", que subiu de 3,200 para 6,400, ou seja,

The global HDI value has increased 20 percent since then, from 0.597 to 0.717 (Human Development Report, 2016, p. 76).

11 No original: The current architecture of international institutions and unbalanced evolution of global markets present challenges to human development on two fronts. Some population segments have progressed, leaving others behind. And unregulated financial globalization has increased people's economic insecurity. Capital tends to be concentrated in the wealthiest segment of the population, which enjoys the benefits of mobility and the increasingly flexible forms of production (global value chains) (tradução livre).

12

No original: There seems to be a widespread view that globalization is good for a small elite but not for the broad masses of people. Even many academics and policymakers who welcomed globalization are revising their opinion. The backlash against globalization is reshaping politics in various countries. But it cannot be rolled back, so the challenge is to ensure that globalization leaves no one behind (tradução livre). 
enquanto a desigualdade global relativa diminuiu $17,4 \%$ a desigualdade global absoluta aumentou $100 \%$.

Para entender a diferença entre estes dois coeficientes basta destacar que, hipoteticamente, se em 2000 uma pessoa em um país ganha $\$ 1$ por dia e outra pessoa $\$ 10$ por dia, com o crescimento econômico, em 2016 a primeira pessoa ganha $\$ 8$ por dia, e a segunda pessoa $\$ 72$ por dia. A diferença relativa entre os dois diminuiu, passando de 1,0 para 0,9 , entretanto, a diferença absoluta subiu de $\$ 9$ para $\$ 64$, ou seja, aumentou $71,1 \%$.

Assim, a partir destes indicadores e medidas de desigualdade de cunho estatístico, que suscitam comparações internacionais e temporais, evidenciou-se que atualmente existe um ambiente favorável para a manutenção das assimetrias globais. E, deste cenário, extrai-se o questionamento central do presente artigo: há prognóstico jurídico para a mitigação destas assimetrias globais?

A simbiose entre direito doméstico e direito internacional destaca a importância deste último, em especial para elaborar mecanismos que visem a solução das assimetrias globais, a fim de assegurar equilíbrio nas relações interestatais entre atores de diferentes níveis de desenvolvimento, para a promoção de um ambiente internacional mais justo e equilibrado, que reflita na melhoria dos países menos desenvolvidos, conforme será demonstrado nos tópicos a seguir.

\section{A REDUÇÃO DAS ASSIMETRIAS GLOBAIS PELA COOPERAÇÃO INTERNACIONAL PARA O DESENVOLVIMENTO: ANÁLISE DO PAPEL DA CNS E DA CSS NA AGENDA GLOBAL}

A cooperação internacional, objeto do presente tópico, é 
princípio geral do direito internacional público ${ }^{13}$, e indica que os Estados devem agir em conjunto, colaborando para a busca de objetivos, com fito de buscar soluções compartilhadas para os problemas que lhes são comuns (VARELLA, 2016, p. 27). Não se trata da anulação total das fronteiras ou abdicação da autonomia, mas de uma nova relação cooperativa entre Estados para buscar soluções diante de problemas que são globais (CENCI, 2007, p. 10).

Com efeito, observa-se que a referida cooperação tem se tornado tema de crescente complexidade e importância em um mundo contemporâneo globalizado, onde as desigualdades se fazem mais visíveis. Países emergentes, assim como organizações intergovernamentais, empresas e organizações da sociedade civil têm passado a desempenhar um papel mais relevante e autônomo nesta cooperação, dada a persistência dos desafios do desenvolvimento global, e contribuído para redefinir a construção de um arcabouço institucional inclusivo que sirva para harmonizar tal princípio (SOARES, 2014, p. 7).

Assim, evidencia-se que o princípio de cooperação internacional, além de ser previsto expressamente como fonte de direito, é um importante instrumento de efetivação de igualdade nos novos relacionamentos interestatais. Ademais, reveste-se de uma precondição ou um corolário para a coexistência pacífica em constante relação com os demais princípios do direito internacional (TRINDADE, 1981, p. 70).

Entretanto, se os princípios gozam de elevada abstração, são necessários meios ou mecanismos de promoção para que seu valor seja concretizado no mundo real. Nas lições de Ian Brownlie (1997, p. 120) são duas as formas de concretização do princípio da cooperação

13 Cumpre ressaltar ainda que o princípio da cooperação internacional se encontra previsto expressamente no ordenamento jurídico brasileiro na Constituição Federal, em seu art. $4^{\circ}$, inciso IX, no qual estão fixados os princípios que regem a República Federativa do Brasil nas relações internacionais. 
internacional: pela cooperação multilateral e pela cooperação bilateral.

Em ambas se envolvem atores ou sujeitos distintos (países, organizações internacionais, agências governamentais e nãogovernamentais), que se subdividem em doadores de um lado e beneficiários do outro (MILANI, 2014, p. 50).

A primeira maneira de concretização se dá por meio da cooperação multilateral, nesse conjunto de relações se pode encontrar organizações multilaterais - as agências do sistema ONU, os bancos de desenvolvimento, além de algumas organizações de caráter não universal, tais como a União Europeia e a $\mathrm{OCDE}$-, agências governamentais e não governamentais (MILANI, 2014, p. 50). Cumpre ressaltar que "o sistema de cooperação técnica para o desenvolvimento da ONU é, cronologicamente, considerado como o primeiro e matriz de todos os demais" (MEDEIROS, 1994, p. 279).

A segunda maneira de materializar os laços de cooperação se consolida justamente por meio da assistência bilateral, ou seja, aquela efetivada entre um país doador em prol de um país beneficiário. Segundo o Relatório de Cooperação para o Desenvolvimento de 2016 (Development Cooperation Report, 2016, p. 58), elaborado anualmente pela Organização para Cooperação e Desenvolvimento Econômico, os países da OCDE canalizaram $40 \%$ da sua cooperação internacional para o sistema de ajuda multilateral, um ligeiro aumento relativamente à média de $2009-2010$ de $38 \%$, sendo que os outros $60 \%$ foram destinados para a cooperação bilateral.

Contudo, as ações e programas que visam à concretização da cooperação internacional para o desenvolvimento (CID), tanto no plano multilateral quanto no plano bilateral, subdividem-se em 02 (duas) espécies de cooperação: Cooperação Norte-Sul (CNS) e Cooperação 
Sul-Sul (CSS).

A primeira vertente de cooperação internacional (CNS) é proporcionada por um grupo de países desenvolvidos denominados doadores, dotados de capacidade financeira, técnica, científica, que tem por objetivo ajudar no desenvolvimento de Estados de outro grupo, compostos por países em desenvolvimento ou menos desenvolvidos, denominados beneficiários.

Assim, a denominação tem relação com a coexistência de partes desiguais na relação, sendo que, não guarda respeito especificamente à divisão geográfica mundial, mas sim a distinção entre países desenvolvidos (Norte) e países menos desenvolvidos ou em desenvolvimento (Sul). No mesmo sentido:

O Sul é aqui concebido metaforicamente como um campo de desafios epistêmicos que procuram reparar os danos e impactos historicamente causados pelo capitalismo na sua relação colonial com o mundo. Esta concepção do Sul sobrepõe-se em parte com o Sul geográfico, o conjunto de países e regiões do mundo que foram submetidos ao colonialismo europeu e que, com exceções como, por exemplo, da Austrália e da Nova Zelândia, não atingiram níveis de desenvolvimento econômico semelhantes ao do Norte global (Europa e América do Norte) (SANTOS, 2010, p. 12-3).

A segunda espécie é chamada de Cooperação Sul-Sul (CSS), por meio da qual os países do sul (menos desenvolvidos e em desenvolvimento) passaram a assimilar que a promoção do desenvolvimento do grupo era viável pela cooperação mútua entre os próprios países do sul. Isto porque, por estarem incluídos em um grupo específico, seus problemas eram comuns. A este aspecto também se soma o movimento de união destes 
países pela descolonização, pela igualdade entre nações e pelo fim de atos de imperialismo dos Países do Norte.

Destarte, em contraste com a cooperação para o desenvolvimento clássica, fornecida pelos países ricos (CNS), a Cooperação Sul-Sul é conceituada como uma "parceria horizontal" entre os países que partilham problemas e desafios comuns de desenvolvimento (STOLTE, 2012, p. 10).

O cenário da cooperação internacional para o desenvolvimento sofreu grandes alterações com o surgimento da Cooperação Sul-Sul, pois, países como Brasil, China, África do Sul, Índia, México e Turquia tornaram qualitativamente mais densa a sua participação no sistema de cooperação internacional para o desenvolvimento, não mais apenas enquanto beneficiários, mas também como doadores (HIRST, 2009, p. 121).

Ademais, a fragmentação da execução da política de cooperação também faz parte das mudanças, isto porque 80 mil novos projetos a cada ano são financiados por pelo menos 42 países doadores por meio de 197 agências bilaterais e 263 organizações multilaterais (KHARAS, 2010, p.4).

Insta salientar que a Cooperação Sul-Sul tem sido apresentada como uma alternativa e não como uma estratégia de substituição obrigatória às políticas de Cooperação Norte-Sul, graças à concepção e implementação de políticas defendidas como sendo mais horizontais, menos assimétricas e fundadas na solidariedade entre países em desenvolvimento (MILANI; CARVALHO, 2013, p. 11).

Portanto, destacam-se como principais características da CSS: a horizontalidade e a equidade. A primeira exige que os países colaborem entre si de maneira voluntária, sem que nenhuma das partes se conecte a outra em virtude de condições. A segunda disciplina que a cooperação 
deve ser exercida a fim de que seus benefícios se distribuam de maneira equitativa entre os participantes (SEGIB, 2008, p. 16) ${ }^{14}$.

Diante deste quadro teórico-conceitual, há que se ressaltar que, no atual cenário mundial, o conjunto de práticas efetivadas no plano fático pautadas na cooperação internacional, que visam concretizar meios eficientes para a superação das assimetrias ou desigualdades globais, estão cada vez mais em evidência, em crescente proliferação ${ }^{15}$.

As ações de CNS e CSS evidenciam uma difusão ampla do reconhecimento da importância da cooperação internacional para o desenvolvimento dos países beneficiários. E, no que diz respeito aos possíveis efeitos ou resultados ocorridos nestes países, tem-se demonstrado que a implementação da CNS e da CSS beneficia os países em desenvolvimento, e, consequentemente, mitigam as assimetrias globais em diversos setores.

Com efeito, sobre o a importância da Cooperação Sul-Sul a OCDE (2010c, p. 73) apontou algumas das evidências que tornam suas políticas essenciais para os países em desenvolvimento, contradizendo críticas ordinárias, tais como as que indicam que a semelhança das estruturas de produção entre os países em desenvolvimento não pode proporcionar complementariedade, mas só competição interna ${ }^{16}$, ou,

14 Ainda quanto ao tema, tem-se que boa parte da engenharia institucional que, desde o começo dos anos 2000, tem sustentado a CSS fundamenta-se no pressuposto de que países em desenvolvimento podem e devem cooperar uns com os outros a fim de garantir reformas políticas da governança global (FMI, Banco Mundial, ONU) e resolver os seus próprios problemas econômicos e sociais com base em identidades compartilhadas (ex-colônias, status econômico, experiência histórica, etc.), esforços comuns, interdependência e reciprocidade (MILANI; CARVALHO, 2013, p. 15).

15 A título de exemplo, no que diz respeito especificamente a Cooperação Sul-Sul do Brasil, segundo dados oficiais da $\mathrm{ABC}$, atualmente, o país mantém relações de cooperação com a América Latina, Caribe e África, com atuações pontuais na Ásia (Timor-Leste, Afeganistão e Uzbequistão), Oriente Médio (Líbano e Territórios Palestinos) e Oceania. Em 2008, a ABC aprovou e coordenou a execução de 236 projetos e atividades de cooperação técnica Sul-Sul, beneficiando 58 países em desenvolvimento (Agência Brasileira de Cooperação-ABC. Disponível em: <http://www.abc.gov.br/Projetos/CooperacaoSulSul $>$. Acesso em: 10 abr. 2017

$16 \quad$ No original: "Is stressed the the endowments and technology structure are relatively similar among developing countries and so, in general, their production 
ainda, que as negociações entre estes países geram mais desvio comercial que crescimento comercial.

A primeira evidência trata especificamente da capacidade da CSS ampliar as criações e negociações comerciais dos países beneficiários no plano global, em virtude de permitir a inserção destes na economia de escala mundial. A OCDE (2010c, p. 73) destaca que:

Na prática, as negociações comerciais regionais SulSul conduzem frequentemente a uma maior criação de comércio do que à desvio. Os ganhos do comércio ocorrem mesmo entre países cujos gostos, tecnologia e doações de fatores são semelhantes onde o comércio é impulsionado por economias de escala. Mayda e Steinberg (2007) não encontraram evidências de que o Mercado Comum para a África Oriental e Austral (COMESA) tenha causado "desvio de comércio". Usando um modelo gravitacional, Korinek e Melatos (2009) sugerem que o AFTA, COMESA e MERCOSUL têm aumentado o comércio de produtos agrícolas entre seus países membros e que esses acordos têm um efeito líquido de criação de comércio. Berthélemy (2009), em um estudo para o Banco Africano de Desenvolvimento, examinou os efeitos sobre o bemestar do comércio China-África e novamente encontrou clara criação comercial durante o período 1996-2007.17

A segunda aborda o estímulo da CSS às exportações pelos países beneficiários, pois devido às suas vantagens em termos de custos, a liberalização comercial pelo modelo de Cooperação Sul-Sul pode tornar os insumos e produtos intermediários mais baratos, fator que, structures will be competitive rather than complementary" (tradução livre).

17 No original: In practise South-South regional trade agreements often lead to greater trade creation than diversion. Gains from trade con occur even between countries whose tastes, technology and factor endowments are similar where trade is driven by economies of scale. Mayda and Steinberg (2007) found no evidence that Common Market for Eastern and Southern Africa (COMESA) caused trade diversion. Using a gravity model, Korinek and Melatos (2009) suggest that AFTA, COMESA and MERCOSUR have increased trade in agricultural products between their member countries and these agreements have a net trade-creation effect. Berthélemy (2009), in a study for African Development Bank, examined welfare effects of China-Africa trade, and found clear trade creation over the period 1996-2007 (tradução livre). 
consequentemente, enseja a melhora da produção para exportação.

Ainda nesta linha, uma terceira evidência diz respeito aos benefícios decorrentes da proximidade geográfica entre os Estados participantes da maioria dos programas de CSS. Isto porque, enquanto os custos da comunicação caíram acentuadamente ao longo de duas ou três décadas, os custos de transporte e outros custos relacionados à distância não têm diminuído, assim, há vantagens no custo da negociação local ou regional ${ }^{18}$.

Em outro estudo da OCDE (2010a, p. 11), o qual teve por objeto a observação de 110 casos de Cooperação Sul-Sul, destacouse que os países em desenvolvimento se tornaram fornecedores e contribuintes para o desenvolvimento de capacidades (em outros países em desenvolvimento), e os seus efeitos estão sendo perceptíveis em uma impressionante variedade de áreas políticas e institucionais, incluindo os relacionados a mudanças climáticas e meio ambiente, reforma do setor público e controle de endemias ${ }^{19}$.

Ademais, a partir de estudos voltados para efeitos da cooperação em prol dos países em desenvolvimento, Frans Lammersen e Michael Roberts (2015, p. 12) sintetizam que:

[...] um aumento de $1 \%$ na ajuda à facilitação do comércio pode gerar um aumento de US\$ 415 milhões no comércio global. Uma avaliação da assistência comercial da USAID (2010) focada na expansão das exportações, nas reformas da política comercial, no aumento da participação nos

$18 \quad$ No original: South-South trade can benefit from proximity - contrary perceptions, while communications costs have fallen sharply over the two or three decades, transport and other distance costs have not $\left(\mathrm{OECD}, 2009^{\mathrm{a}}\right)$. Hence, there are still cost advantages in trading local (tradução livre).

19 No original: Indeed, developing countries are becoming providers and contributors to development and, in particular, to capacity development. As we will see in the following pages, Southern officials and experts are exchanging knowledge in an impressive array of policy and institutional areas, including climate change, public sector reform, and epidemics control (tradução livre). 
acordos comerciais e nos ganhos de eficiência resultantes da facilitação do comércio, conclui que cada dólar aumenta o valor das exportações dos países em desenvolvimento em USD42 dois anos depois. A OCDE/OMC (2013a) diz que um dólar norte-americano investido em ajuda ao comércio está associado, em média, a um aumento de quase oito dólares norte-americanos nas exportações de todos os países em desenvolvimento e a um aumento de 20 dólares nas exportações dos países mais pobres ${ }^{20}$.

Assim, em face da proposta do presente subitem, resta claro que por meio das políticas e programas de cooperação internacional para o desenvolvimento na modalidade de CSS, ferramentas de desenvolvimento adaptadas estão sendo projetadas e disseminadas em todo o mundo, como transferências monetárias condicionais, estratégias de desmobilização e reintegração, gestão da dívida pública, moradia resistente a terremotos, segurança da aviação e produção de vacinas (OCDE, 2010a, p. 73) ${ }^{21}$.

\section{O TRATAMENTO ESPECIAL E DIFERENCIADO COMO INSTRUMENTO CONCRETIZADOR DA IGUALDADE MATERIAL PARA MITIGAÇÃO DAS ASSIMETRIAS NO PLANO INTERNACIONAL}

A análise do denominado Tratamento Especial e Diferenciado (TED) no âmbito do Sistema Multilateral do Comércio como mecanismo

20 No original: [...] a $1 \%$ increase in aid for trade facilitation could generate a USD 415 million increase in global trade. An evaluation of USAID (2010) trade assistance that focused on export expansion, trade policy reforms, increased participation in trade agreements, and efficiency gains from trade facilitation assistance, finds that each additional one US dollar increases the value of developing country exports by USD 42 two years later. OECD/WTO (2013a) finds that one US dollar invested in aid for trade is on average associated with an increase of nearly eight US dollars in exports from all developing countries and an increase of twenty US dollars in exports from the poorest countries (tradução livre).

21 No original: Adapted development tools are being designed by and spread throughout the developing world, such as conditional cash transfers, demobilization and reintegration strategies, public debt management, earthquake-resistant housing, aviation security, and vaccines production. (tradução livre) 
para a atenuação das assimetrias globais em prol dos países menos desenvolvidos (least developed countries) e em desenvolvimento (developing countries), especialmente nas relações comerciais internacionais, é o que se propõe no presente tópico.

Com efeito, o TED tem por objetivo justamente a tentativa de corrigir as assimetrias do comércio internacional e atenuar as disparidades econômicas entre os países participantes do comércio, por meio da introdução de tratamentos preferenciais em favor dos Estados que ainda não atingiram um nível de desenvolvimento suficientemente elevado que os permitissem encarar o comércio internacional em igualdade de condições com os países desenvolvidos (GIBBS, 2000, p. 73).

Assim, o conceito de TED está alicerçado na perspectiva da igualdade material, pela qual se defende que apenas um tratamento desigual pode corrigir desigualdades entre partes distintas. Nesta linha, tem-se que a implementação do TED, na medida em que promove a igualdade e não a desigualdade, garante a possibilidade de contrabalançar algumas assimetrias inerentes à globalização (RAJAMANI, 2006, p. 6) ${ }^{22}$.

Para tanto, a fim de garantir um cenário de atenuação das desigualdades, o TED se baseia, primeiramente, em acentuar as condições de acesso a mercados aos países em desenvolvimento e menos desenvolvidos, e, em segundo, dispensá-los de certas regras do comércio multilateral a fim de garantir maior flexibilidade no uso de medidas comerciais (OYEJIDE, 2002).

Assim sendo, resta evidente que se trata de instrumento que mitiga a regra estabelecida pelo princípio da não-discriminação do GATT, pois implica, justamente, na discriminação de países em desenvolvimento,

22 No original: "Differential treatment, in so far as it furthers equality rather than entrenches inequality, has the potential to counterbalance some of inequities inherent in globalization [...]" (tradução livre). 
ou seja, garante um tratamento especial e diferenciado que favorece os países em desenvolvimento ou menos desenvolvidos em detrimento dos países desenvolvidos.

A justificativa do tratamento especial e diferenciado está alicerçada no conceito de que a oportunidade de participação no comércio internacional deve induzir ganhos como consequência do uso deste modelo de tratamento, mas, além disso, deve promover justiça na distribuição desses ganhos, por meio de relações mutuamente vantajosas para países com níveis de desenvolvimento diversos e características peculiares (SALDANHA, 2012, p. 20).

Por essa perspectiva, depreende-se que por um tratamento especial e diferenciado legitimado nas relações que se desenvolvem no ambiente de integração interestatal, que vise um melhor desempenho dos países menos desenvolvidos ou em desenvolvimento no âmbito do comércio internacional, garante, em primeiro lugar, o fortalecimento da economia interna destes países.

Mas, além deste fator e mais importante que este, compreende-se que a maximização do potencial destes Estados-membros no comércio mundial gera reflexos diretos para outras áreas do país atuante, como a intensificação das atividades domésticas para exportação, incremento de valor aos fatores internos de produção, elevação nos níveis de investimento, promoção da base tecnológica e científica, aumento do emprego e de oportunidades de empreendimento, redução da dependência estrangeira e alívio da dívida externa.

Os artigos do GATT que compõem a política de TED estão previstos na Parte IV (Artigos XXXVI e XXXVIII) e também na “Cláusula de Habilitação" (Enabling Clause). O Artigo XXXVI revela o reconhecimento dos membros do GATT de que para os países em 
desenvolvimento há uma maior urgência na concretização dos seus objetivos fundamentais - aumento do nível de vida e o desenvolvimento progressivo das economias ${ }^{23}$ - e de que os ganhos de exportação das partes contratantes menos desenvolvidas podem desempenhar um papel vital no seu desenvolvimento econômico ${ }^{24}$.

Para tanto, como instrumento para garantir tratamento distinto em benefício dos países menos desenvolvidos, o parágrafo 8 do Artigo XXXVI prescreve que “[...] as partes contratantes desenvolvidas não esperam reciprocidade dos compromissos assumidos por eles nas negociações comerciais para reduzir ou remover as tarifas e outros obstáculos ao comércio das partes contratantes menos desenvolvidas" 25 . Já o Artigo XXXVIII do GATT, por sua vez, prevê expressamente a necessidade da adoção de ações, por meio de acordos internacionais, para proporcionar condições de acesso melhoradas e aceitáveis ao mercado mundial para os produtos primários de interesse particular dos países contratantes menos desenvolvidos, bem como para conceber medidas destinadas à melhoria das condições do mercado mundial para a exportação destes produtos ${ }^{26}$.

Ademais, no âmbito da previsão de TED junto ao GATT, tem-se

$23 \quad$ No original: " recalling that the basic objectives of this Agreement include the raising of standards of living and the progressive development of the economies of all contracting parties, and considering that the attainment of these objectives is particularly urgent for less-developed contracting parties" (tradução livre).

24

No original: "considering that export earnings of the less-developed contracting parties can play a vital part in their economic development" (tradução livre).

25 No original: 8 . The developed contracting parties do not expect reciprocity for commitments made by them in trade negotiations to reduce or remove tariffs and other barriers to the trade of less-developed contracting parties (tradução livre).

26 No original: In particular, the contracting parties shall: where appropriate, take action, including action through international arrangements, to provide improved and acceptable conditions of access to world markets for primary products of particular interest to less-developed contracting parties and to devise measures designed to stabilize and improve conditions of world markets in these products including measures designed to attain stable, equitable and remunerative prices for exports of such products (tradução livre) 
ainda a denominada Cláusula de Habilitação ou Enabling Clause, extraída da Decisão dos países-membros do GATT, de 28 de novembro de 1979²7, que permite derrogações à Cláusula da Não-discriminação, ao prever que sem prejuízo do disposto no artigo I do GATT, as partes contratantes podem conceder um tratamento diferenciado e mais favorável aos países em desenvolvimento, sem que tal tratamento seja dado às outras partes contratantes.

Dentre as medidas possíveis de serem tomadas, o parágrafo 2 da referida decisão prevê as seguintes: tratamento pautal preferencial concedido pelas partes contratantes desenvolvidas a produtos originários de países em desenvolvimento, em conformidade com o Sistema Geral de Preferências ${ }^{28}$; tratamento diferenciado e mais favorável relativamente às disposições do Acordo Geral relativas a medidas não pautais regidas pelas disposições dos instrumentos multilateralmente negociados sob os auspícios do GATT; acordos regionais ou globais celebrados entre as partes contratantes menos desenvolvidas para a redução ou eliminação mútua de tarifas e, de acordo com critérios ou condições que podem ser prescritos pelas partes contratantes, para a redução ou eliminação mútua de medidas não-tarifárias, sobre os produtos importados entre si; tratamento especial dos países menos desenvolvidos entre os países em desenvolvimento no contexto de medidas gerais ou específicas em favor dos países em desenvolvimento.

Com efeito, ainda no tocante as medidas de TED para países

27 Disponível em: https://www.wto.org/english/docs_e/legal_e/enabling1979_e.htm. Acesso em: 16 abr. 2017.

28 O Sistema Geral de Preferências (SGP) foi originariamente adotado pela Conferência da UNCTAD em Nova Delhi, em 1968, por meio da qual se garantem tarifas especiais de acesso ao mercado para uma seleção de produtos oriundos de países em desenvolvimento. Em 1971, os países do GATT adotaram o SGP por um período de dez anos. Porém, durante a Rodada de Tóquio, entre 1973 e 1979, asseguraram a permanência do SGP junto ao GATT, ao adotarem a Cláusula de Habilitação (Enabling Clause) (SAKR, 2010, p. 336). 
em desenvolvimento ou menos desenvolvidos no âmbito de regulação da OMC, destacam-se as seguintes: acesso preferencial no mercado, tarifas com períodos mais longos e progressivos, flexibilidade na implementação das disciplinas da OMC, ofertas dos países desenvolvidos para fornecer assistência técnica e capacitação para os países em desenvolvimento para facilitar a implementação dos acordos da OMC (ISMAIL, 2005, p. 213$)^{29}$.

A previsão expressa de mecanismos ou instrumentos de implementação do Tratamento Especial e Diferenciado (TED) no corpo de acordos, decisões e declarações da OMC difundiu-se muito nos últimos tempos, a ponto de a organização compilar as prescrições em um documento único, qual seja o WT/COMTD/W/219 de 22 de setembro de $2016^{30}$, sob recomendação do Comitê de Comércio e Desenvolvimento (Committee on Trade and Development-CTD).

Assim sendo, destaca-se que as benfeitorias e o aumento dos ganhos gerados pelo comércio para os países em desenvolvimento ou menos desenvolvidos com a concretização do TED, além de ser de interesse deles próprios, também o é dos países mais desenvolvidos, por dois principais motivos: a) diante da saturação do crescimento da demanda interna em alguns países desenvolvidos, os países em desenvolvimento e os menos desenvolvidos constituem um reservatório de demanda inexplorada (externa) que, se incentivada, irá garantir ímpeto exponencial ao crescimento do comércio internacional e à expansão da economia mundial; b) o aumento da competitividade em face do

$29 \quad$ No original: "Special and differential treatment (SDT) measures for developing countries in the World Trade Organization (WTO) include preferential market access, longer tariff phase-down periods and flexibility in the implementation of WTO disciplines, and offers by developed countries to provide technical assistance and capacity building to developing countries to facilitate the implementation of WTO agreements". (Tradução livre)

$30 \mathrm{O}$ texto original do documento está disponível em: <file://C:/Users/Igor/Downloads/W219. pdf>. Acesso em: 11 jun. 2017. 
desenvolvimento dos demais países do mundo é capaz de ensejar o bemestar das economias, pela redução do preço de produtos e matéria-prima, fortalecendo o mercado global e expandindo a capacidade produtiva dos atores do sistema multilateral do comércio (MUNIZ; BAPTISTA, 2016, p. 125).

Portanto, evidencia-se que uma política baseada no tratamento especial e diferenciado, estimularia o crescimento e aumentaria o bemestar econômico internacional, tanto para os países desenvolvidos como para países em desenvolvimento ou menos desenvolvidos, possibilitando um sistema baseado na concepção de justiça no comércio internacional (ISMAIL, 2005, p. 214), e, consequentemente, implica na mitigação das assimetrias globais.

\section{CONCLUSÃO}

$\mathrm{O}$ artigo fixou um mapa cognitivo baseado na observação das assimetrias globais por meio de uma perspectiva multidisciplinar do objeto central. Para tanto, optou-se por uma construção da pauta hermenêutica, valorizando a interpretação da realidade socioeconômica utilizando o direito internacional contemporâneo como base teórica em conjunto com a análise de dados que evidenciam, com critérios objetivos e subjetivos, as desigualdades presentes no dinamismo do desenvolvimento dos países no atual cenário global.

Neste contexto, em face da comprovação da presença de assimetrias globais, questionou-se acerca da possibilidade de um prognóstico jurídico capaz de mitigar as desigualdades existentes entre os níveis socioeconômicos dos Estados no plano internacional.

Ainda que diante de implicações que representam a necessidade de uma investigação contínua para a busca de uma solução definitiva, 
concluiu-se que a mitigação das assimetrias globais é possível por meio:

a) da concretização do princípio jurídico da cooperação internacional para o desenvolvimento, pela adoção de um modelo global de práticas mais solidárias, pois, conforme os marcos teóricos e as fundamentações ponderadas no segundo tópico:

a.1) tanto a Cooperação Norte-Sul quanto a Cooperação Sul-Sul implicam na atuação conjunta de Estados em prol do desenvolvimento de países menos desenvolvidos ou em desenvolvimento, diminuindo a disparidade na distribuição de renda (diminuindo a concentração da riqueza) e elevando o Índice de Desenvolvimento Humano;

a.2) os benefícios decorrentes da cooperação internacional refletem em desenvolvimento de diversas áreas, não se fixando somente no ponto de vista econômico, pois seus efeitos são perceptíveis nas áreas políticas e institucionais, no campo das mudanças climáticas e meio ambiente, no desenvolvimento de remédios e no controle de endemias;

b) da implementação do tratamento especial e diferenciado como instrumento jurídico no âmbito do comércio internacional, pois, conforme discorrido ao longo do terceiro tópico:

b.1) o tratamento especial e diferenciado visa assegurar equilíbrio nas relações negociais entre atores de diferentes níveis de desenvolvimento para a promoção de um Sistema Multilateral do Comércio mais justo, por meio da adoção do conceito de isonomia material, para garantir um tratamento distinto em prol dos países em desenvolvimento e menos desenvolvidos, em verdadeira 
exceção ao princípio da não-discriminação do GATT;

b.2) o tratamento especial e diferenciado permite o acesso preferencial dos países menos desenvolvidos e em desenvolvimento no mercado internacional, por meio de tarifas com prazos mais longos e progressivos, de flexibilidade na implementação das regras da $\mathrm{OMC}$, de ofertas dos países desenvolvidos para fornecer assistência técnica e capacitação para facilitar a implementação dos acordos da OMC, que, portanto, visam corrigir as desigualdades no comércio internacional e, consequentemente, implicar na mitigação das assimetrias globais.

\section{REFERÊNCIAS}

BRASIL. Constituição da República Federativa do Brasil:

promulgada em 5 de outubro de 1988. Disponível em: $<$ http://www. planalto.gov.br/ccivil_03/constituicao/ConstituicaoCompilado.htm>. Acesso em: 10 de abr. 2017.

. Agência Brasileira de Cooperação - ABC. Histórico.

Disponível em: <http://www.abc.gov.br/SobreAbc/Historico>. Acesso em 13 abr. 2017.

BROWNLIE, Ian. Princípios de Direito Internacional Público. Lisboa: Editora Fundação Calouste Gulbenkian, 1997.

CENCI, Elve Miguel. Globalização, Estado-nação e regimes supranacionais. In: XVI Encontro Preparatório do CONPEDI, 2007, Campos dos Goytacazes. Anais CONPEDI/Campos dos Goytacazes. Florianópolis: Fundação Boiteux, 2007. v. I. Disponível em: <http:// 
www.publicadireito.com.br/conpedi/manaus/arquivos/anais/campos/ elve_miguel_cenci.pdf $>$. Acesso em: 23 dez. 2016.

CHOSSUDOVSKY, Michel. A globalização da pobreza e a nova ordem mundial. Traduzido por Ana Saldanha. Lisboa: Editorial Caminho, 2003.

COSTA, Antonio Firmino da. Desigualdades globais. In: Sociologia, problemas e práticas, $\mathrm{n}^{\circ} 68,2012$, p. 9-32. Disponível em: $<$ https:// spp.revues.org/650>. Acesso em: 08 abr. 2017.

\section{CREDIT SUISSE RESEARCH INSTITUTE. Global Wealth} Report, 2016. Disponível em: $<$ http://publications.credit-suisse. com/tasks/render/file/index.cfm?fileid=AD783798-ED07-E8C24405996B5B02A32E>. Acesso em: 07 abr. 2017.

. Global Wealth Report, 2010. Disponível em:

$<$ https://publications.credit-suisse.com/tasks/render/file/index. cfm?fileid=88DC32A4-83E8-EB92-9D57B0F66437AC99>. Acesso em: 08 abr. 2017.

GATT - General Agreement on Tariffs and Trade. Disponível em: https://www.wto.org/english/docs_e/legal_e/gatt47_e.pdf. Acesso em: 23 mar. 2017.

GIBBS, Murray. Special and Differential Treatment in the context of Globalization. In: UNCTAD, A Positive Agenda and Future Trade Negotiations. New York and Geneva, 2000. Disponível em:

HIRST, M. Países de renda média e a cooperação Sul-Sul: entre o conceitual e o político. In: LIMA, M. R. S.; HIRST, M. (Org.). Brasil, Índia e África do Sul: desafios e oportunidades para novas parcerias. São Paulo: Paz e Terra, 2009.

ISMAIL, Faizel. Mainstreaming Economic Development in the 
Trading System. In: EVENETT, Simon J.; HOEKMAN, Bernard M.. Economic Development \& multilateral Trade Cooperation, 2006, p. 213-228.

KASTENG, Jonas; KARLSON, Arne; LINDBERG, Carina. Differentiation between developing countries in the WTO. 2004. Disponível em: <http://www2.jordbruksverket.se/webdav/files/SJV/ trycksaker/Pdf_rapporter/ra04_14E.pdf >. Accesso em: 08 abr. 2017.

KHARAS, H. Can aid catalyze development? In: MAKING development aid more effective. Washington D. C.: The Brookings Institute, 2010, p. 3-9.

LAMMERSEN, Frans; ROBERTS, Michael. Aid for trade ten years on: keeping it effective. In: OECD Development Policy Papers, $n$. 1, 2015. Disponível em: http://www.keepeek.com/Digital-AssetManagement/oecd/development/aid-for-trade-10-years-on-keeping-iteffective_5jrqc6q4xxr5-en\#.WO_TjPkrLIU. Acesso em: 13 abr. 2017.

LOPES, Inez. Breves considerações sobre os princípios constitucionais das relações internacionais. In: Consilium - Revista Eletrônica de Direito, Brasília/DF, n.3, v.1, 2009. Disponível em: $<$ http://www.unieuro.edu.br/sitenovo/revistas/downloads/ consilium_03_22.pdf $>$. Acesso em 09 de mar. 2016.

MEDEIROS, Antônio Paulo Cachapuz de. As Organizações Internacionais e a Cooperação Técnica. In: MARCOVITH, Jacques (Org.). Cooperação Internacional: estratégia e gestão. São Paulo: Editora d Universidade de São Paulo, 1994, p. 149-163.

MILANI, Carlos R. S. Evolução histórica da cooperação norte-sul. In: Repensando a cooperação internacional para o desenvlovimento. MELLO E SOUZA, Andre (org.). Brasília: Ipea, 2014. Disponível em: http://www.ipea.gov.br/portal/images/stories/PDFs/livros/livros/ 
repensando_a_cooperacao_web.pdf. Acesso em: 11 abr. 2017.

; CARVALHO, Tassia Camila de Oliveira. Cooperação SulSul e Política Externa: Brasil e China no continente africano. In: Estudos Internacionais, v. 1, n. 1, jan/jun. 2016, p. 11-35. Disponível em: <http:/periodicos.pucminas.br/index.php/estudosinternacionais/ article/view/5158>. Acesso em: 12 abr. 2017.

MUNIZ, Tânia Lobo; BAPTISTA, Rudá Ryuiti Furukita. As Linhas Diretrizes da OCDE para as empresas multinacionais e sua implementação no Direito Brasileiro. In: Direito Internacional em expansão, Vol. VII. MENEZES, Wagner (org.). Belo Horizonte: Arraes, 2016, p. 114-129.

OECD - The Organisation for Economic Co-operation and Development (OCDE - Organização para a Cooperação e Desenvolvimento Econômico). Development Co-operation Report, 2016a. Disponível em: http://www.keepeek.com/DigitalAsset-Management/oecd/development/development-co-operationreport-2016_dcr-2016-en\#page158. Acesso em: 12 abr. 2017.

\section{. Boosting South-South Cooperation in the context of} aid effectiveness, 2010a. Disponível em: <http://www.oecd.org/dac/ effectiveness/46080462.pdf>. Acesso em: 13 abr. 2017.

\section{. Development finance of countries beyond the DAC,}

2014. Disponível em: <http:/www.oecd.org/dac/stats/non-dacreporting.htm>. Acesso em: 14 abr. 2017.

. Estimates of the development co-operation programmes of: Brazil, Chile, China, Colombia, Costa Rica India, Indonesia, Mexico, Qatar and South Africa, 2016b. Disponível: http://www. oecd.org/dac/stats/non-dac-reporting.htm. Acesso em: 12 abr. 2017. 
. Is it ODA?. Facsheet, Nov. 2008. Disponível em: $<$ http:// www.oecd.org/dac/stats/34086975.pdf>. Acesso em: 12 abr. 2017.

. The China-DAC Study Group, 2016c. Disponível em: http://www.oecd.org/dac/dac-global-relations/china-dac-study-group. htm. Acesso em: 14 abr. 2017.

. The DAC: 50 years, 50 highlights, 2010b. Disponível em: http://www.oecd.org/dac/46717535.pdf. Acesso em: 12 abr. 2017.

\section{. Query Wizard for International Development Statistics}

(QWIDS). Disponível em: < https://stats.oecd.org/qwids/>. Acesso em: 12 abr. 2017.

ONU - Organização das Nações Unidas. Carta das Nações Unidas de 1945. Disponível em: $<$ https://nacoesunidas.org/carta/ $>$. Acesso em: 11 abr. 2017.

OYEJIDE, T.A. Special and Differential Treatment. In: Development, Trade and the WTO. A Handbook. Ed. By B.Hoekman, A. Matoo, and P.English, World Bank. Washing!on.D.C., 2002.

PIOVESAN, Flavia (coord.). Direitos humanos, globalização econômica e integração regional: desafios do direito constitucional internacional. São Paulo: Max Limonad, 2002.

RAJAMANI, Lavanya. Differential treatment in international environmental law. New York: Oxford University Press, 2006.

SAKR, Rafael Lima. A Cláusula da Nação Mais Favorecida na Ordem Econômica Internacional: uma investigação sobre o discurso jurídico do Artigo I: 1 do GATT. 382 p. Dissertação (Mestrado). Universidade de São Paulo. Disponível em: http://www. teses.usp.br/teses/disponiveis/2/2135/tde-26092011-140858/pt-br.php. 
Acesso em: 18 jun. 2017.

SALDANHA, Eduardo. Desenvolvimento e tratamento especial e diferenciado na OMC: uma abordagem sob a perspectiva da doutrina do stare decisis - Parte I. In: Revista Direito Econômico Socioambiental, v. 3, n. 1, p. 11-42, jan/jun. 2012.

SANTOS, Boaventura de Souza. Para além do pensamento abissal: das linhas globais a uma ecologia de saberes. In: SANTOS, B.S $\&$ MENEZES, M. P. Epistemologias do sul. 2 ed. Coimbra: CES, 2010. Disponível em: $<$ http://www.scielo.br/scielo.php?script=sci arttext\&pid=S0101-33002007000300004>. Acesso em: 11 abr. 2017.

SEGIB. Secretaria General Iberoamericana. II Informe de la Cooperación Sur-Sur en Iberoamérica. Madrid: Segib. 2008.

SOARES, Sergei Suarez Dillon. Apresentação. In: Repensando a cooperação internacional para o desenvlovimento. MELLO E SOUZA, Andre (org.). Brasília: Ipea, 2014. Disponível em: http://www.ipea.gov.br/portal/images/stories/PDFs/livros/livros/ repensando_a_cooperacao_web.pdf. Acesso em: 11 abr. 2017.

SOUZA, Nali de Jesus de. Desenvolvimento Econômico. 6 ed. São Paulo: Atlas, 2012.

SPOSATI, Aldaíza. Globalização: um novo e velho processo. In: DOWBOR, Ladislau; IANNI, Octavio; RESENDE, Paulo-Edgar A. (orgs.). Desafios da globalização. Petrópolis: Vozes, 1997.

STOLTE, Christina. Brazil in Africa: Just Another BRICS Country Seeking Resources? Londres: Chatham House. 1 nov. 2012.

Disponível em: <http://www.chathamhouse.org/publications/papers/ view/186957>. Acesso em: 30 mar. 2016. 
THERBORN, Göran. Os campos de extermínio da desigualdade.

Traduzido por: Fernando Rugistiky. In: Novos Estudos, 2010.

Disponível em: <http://www.scielo.br/pdf/nec/n87/a09n87.pdf > . Acesso em: 09 abr. 2017.

TRINDADE, Antonio Augusto Cançado. Princípios do Direito Internacional Contemporâneo. Brasília: Universidade de Brasília, 1981.

UN - UNITED NATIONS. The least developed countries report 2014. New York and Geneva, 2014. Disponível em: <http://unctad. org/en/PublicationsLibrary/ldc2014overview_en.pdf $>$. Acesso em: 15 abr. 2017.

UNCTAD - United Nations Conference on Trade and Development. Disponível em: $<$ http://unctad.org/en/Pages/AboutUs.aspx $>$. Acesso em: 15 abr. 2017.

. Trade and Development Report, 2006. Disponível em: $<$ http://unctad.org/en/Docs/tdr2006_en.pdf $>$. Acesso em: 30 mar. 2017.

. Gross Domestic Product, 2012. Disponível em: $<$ http:// dgff.unctad.org/annexes/def.html\#GDP>. Acesso em: 10 abr. 2017.

. South-South Cooperation: Africa and the New Forms of Development Partnership. Genebra, 2010. Disponível em: http:// unctad.org/en/Docs/aldcafrica2010_en.pdf. Acesso em: 12 abr. 2017.

UNDP - United Nations Development Programme. Human Development Report, 2016. Disponível em: $<\mathrm{http}$ ://www.undp.org/ content/undp/en/home/librarypage/hdr/2016-human-developmentreport.html>. Acesso em: 09 abr. 2017. 
. Human Development Report 2015. Nova Iorque, 2015. Disponível em: <http://hdr.undp.org/sites/default/files/2015_human development_report.pdf $>$. Acesso em: 14 abr. 2017.

VARELLA, Marcelo Dias. Direito Internacional Público. 6 ed. São Paulo: Saraiva, 2016.

World Bank. World Development Report 2015: Mind, Society and Behavior. <Disponível em: http://www.worldbank.org/en/publication/ wdr2015>. Acesso em: 09 abr. 2017.

. Gross domestic product 2015. Disponível em: $<$ http:// databank.worldbank.org/data/download/GDP.pdf > . Acesso em: 13 abr. 2017.

Como citar: BAPTISTA, Rudá Ryuiti Furukita. MUNIZ, Tânia Lobo. A mitigação das assimetrias globais socioeconômicas pela cooperação internacional e pelo tratamento especial diferenciado. Revista do Direito Público, Londrina, v. 12, n. 3, p.279-314, dez. 2017. DOI: 10.5433/1980-511X2017v12n3p279. ISSN: 1980-511X.

Recebido em: 16/09/2017

Aprovado em: 11/12/2017 